\title{
Sistem Peramalan Harga Emas Antam Menggunakan Double Exponential Smoothing
}

\author{
Teguh Andriyanto \\ Sistem Informasi Universitas Nusantara PGRI Kediri \\ Kediri, Indonesia \\ E-mail: teguh@unpkediri.ac.id
}

\begin{abstract}
Abstrak - Emas merupakan salah satu barang investasi jangka panjang. Harga emas setiap saat dapat berubah. Bagi seseorang yang berinvestasi dalam bentuk emas tentunya membutuhkan informasi perubahan harga emas sehingga dia dapat menentukan kapan harus membeli atau menjual emas. Tanpa adanya informasi yang akurat tentunya akan sulit untuk menentukan berapa nilai atau harga emas beberapa bulan atau tahun kedepan. Dalam penelitian ini dibangun prototipe sistem informasi peramalan harga emas Antam. Data his toris bulanan harga emas Antam didownload dari situs resmi Antam dalam format excel. Selanjutnya file excel tersebut di upload dan diproses untuk menenttukan ramalan harga emas beberapa periode kedepan. Sistem informasi peramalan dibangun menggunakan bahasa pemrograman PHP dan database MySql. Hasil pengujian kesalahan pe ramalan menunjukkan keakuratan pe ramalan sebesar $87,34 \%$. Dara 78 data harga dan peramalan didapatkan 60 data nilai tracking signal be rada diluar batas-batas pengendalian.
\end{abstract}

Kata Kunci-Double Smoothing, Peramalan, Emas Antam

\section{Pendahuluan}

Emas merupakan salah satu barang yang dijadikan sebagai investasi jangka panjang. Harga emas setiap saat dapat berubah. Hal ini tentunya menimbulkan ketidakpastian nilai investasi. Bagi seseorang yang berinvestasi dalam bentuk emas tentunya membutuhkan informasi perubahan harga emas sehingga dia dapat menentukan kapan harus membeli atua menjual emas. Tanpa adanya informasi yang akurat tentunya akan sulit untuk menentukan berapa nilai atau harga emas beberapa bulan atau tahun kedepan.

Berdasarkan permasalahan tersebut maka dalam penelitian ini akan dibangun sistem informasi peramalan harga emas. Harga emas yang yang akan diramalkan adalah emas Antam yang diproduksi oleh PT Antam (Persero) Tbk. Data harga emas diambil dari situs historis harga Antam [1].

Penelitian mengenai peramalan telah banyak dilakukan. Anggraini menggukaan metode Single Exponential Smoothing untuk meramalkan permintaan kebutuhan yang selanjutnya digunakan untuk menentukan jumlah barang yang akan dipesan kepada supplier dengna pendekatan continous review policy [2]. Penelitian serupa juga dilakukan oleh Andriyanto yang menggunakan metode Triple 
Exponential Smoothing untuk meramalkan permintaan barang dengan pola penjualan musiman untuk selanjutnya digunakan untuk proses selanjutnya yaitu inventory control dengan pendelatan periodic review policy [3]. Peneliti yang sama juga menggunakan Adaptive Rate Response Single Exponential Smoothing untuk meramalkan permintaan barang guna pengendalian persediaan barang pada periodic review policy [4]. Double Exponential Smoothing juga digunakan oleh $\mathrm{Wu}$ untuk meramalkan harga babi di China[5].

Sementara itu Riyadi dalam penelitiannya membuat sistem informasi penjualan obat pada Instalasi Farmasi RSUD dr. Munjani [6]. Aplikasi peramalan juga dibuat oleh Baktiar melalui penelitiannya menggunakan Weighted Moving Average dan Double Exponential Smoothing [7]. Aplkasi tersebut dibangun menggunakan bahasa pemrograman php dan basisdata MySql. Sedangkan Wahyani membandingkan metode Exponential Smoothing dan Regresi Linier menggunakan software QM for Windows [8]. Peramalan tersebut digunakan sebagai alat bantu untuk menentukan perencanaan produksi di PT. SKK.

\section{Metode Penelitian}

A. Double Exponential Smoothing Dua Parameter dari Holt

Pada metode Double Exponential Smoothing (DES) dari Holt, nilai trend dimuluskan dengan parameter yang berbeda dari parameter yang digunakan pada deret asli. Ramalan dari DES Holt didapat dengan menggunakan dua konstanta pemulusan (dengan nilai antara 0 dan 1) dan tiga persamaan [9]:

Pemulusan awal

$$
S_{t}=\alpha X_{t}+(1-\alpha)\left(S_{t-1}+b_{t-1}\right)
$$

Pemulusan trend

$$
b_{t}=\gamma\left(S_{t}-S_{t-1}\right)+(1-\gamma) b_{t-1}
$$

Ramalan kedepan

$$
F_{t+m}=\left(S_{t}+m b_{t}\right)
$$

Keterangan:

$$
\begin{array}{ll}
X & =\text { data observasi } \\
S & =\text { smoothed observation } \\
b & =\text { trend factor } \\
t & =\text { time period index } \\
\alpha, \gamma & =\text { konstanta yang harus diperkirakan dengan kesalahan minimal. } \\
F & =\text { ramalan untuk } m \text { periode }
\end{array}
$$

Salah satu masalah dalam menentukan nilai untuk a,b dan g untuk meminimumkan MSE atau MAPE. Pendekatan untuk menentukan nilai-nilai tersebut biasanya dilakukan dengan cara trial and error, walaupun mungkin juga bisa digunakan algoritma optimasi non-linier. Metode ini jarang digunakan karena memakan banyak waktu dan tenaga. Medote ini baru dipakai jika data yang ditangani banyak. 
Jurnal INTENSIF, Vol.1, No.1, Februari 2017

ISSN: $2549-6824$

Proses Inisialisasi DES membutuhkan dua taksiran yaitu $S_{l}$ dan $b_{1}$. Nilai awal $S_{l}=X_{1}$. Sedangkan nilai awal $b_{1}=X_{2}-X_{1}$.

B. Pengujian Peramalan

Untuk menguji hasil peramalan terdapat beberapa metode pengujian sebagai berikut:

1. Ukuran Statistik Standart

Pada pengukuran statistik standart, Jika Xi merupakan data aktual untuk periode i dan Fi merupakan ramalan untuk periode yang sama, maka e atau kesalahan dapat didefinisikan dengan persamaan (4)

$$
\text { e=X_i-F_i }
$$

Jika terdapat nilai pengamatan dan ramalan untuk $n$ periode waktu, maka akan terdapat $n$ kesalahan dan ukuran standar berikut yang dapat didefinisikan dalam persamaan (5), (6), (7) dan (8)

a) Nilai tengah kesalahan (mean error) dapat dihitung dengan menggunakan persamaan (5)

$$
M E=\sum_{i=1}^{n} \frac{\theta_{i}}{n}
$$

b) Nilai tengah kesalahan absolute (mean absolute error) dapat dihitung dengan menggunakan persamaan (6)

$$
M A E=\sum_{i=1}^{n} \frac{\left\|\varepsilon_{i}\right\|}{n}
$$

c) Jumlah kuadrat kesalahan (sum of squared error) dapat dihitung dengan menggunakan persamaan

$$
S S E=\sum_{i=1}^{n} e_{i}^{2}
$$

d) Nilai tengah kesalahan kuadrat (mean squared error) dapat dihitung dengan menggunakan persamaan (8)

$$
M S E=\sum_{i=1}^{n} \frac{\theta_{i}^{2}}{n}
$$

2. Ukuran-ukuran Relatif

Ukuran relatif digunakan untuk menghitung kesalahan prosentas setiap periode waktu. Tiga ukuran relatif yang sering digunakan adalah sebagai berikut:

a) Nilai kesalahan prosentas (percentage error) dapat dihitung dengan menggunakan persamaan (9)

$$
P E_{\mathrm{t}}=\left(\frac{x_{\mathrm{t}}-\vec{F}_{\mathrm{t}}}{x_{\mathrm{t}}}\right)(100)
$$

b) Nilai tengah kesalahan prosentase (mean percentage error) dapat dihitung dengan menggunakan persamaan (10)

$$
M P E=\sum_{t=1}^{n} \frac{P E_{t}}{n}
$$

c) Nilai tengah kesalahan prosentase absolut (mean absolute procentage error) dapat dihitung dengan menggunakan persamaan (11)

$$
\text { MAPE }=\sum_{t=1}^{n} \frac{\left\lfloor P E_{\mathrm{t}}\right\rfloor}{n}
$$


Jurnal INTENSIF, Vol.1, No.1, Februari 2017

ISSN: $2549-6824$

\section{Tracking Signal}

Tracking signal merupakan suatu ukuran bagaimana sebuah ramalan memperkirakan nilainilai aktual. Tracking signal dihitung sebaggai running sum of the forecast error (RSFE) dibagi dengan mean absolute deviation (MAD) sebagai berikut:

$$
\begin{aligned}
& T S=\frac{\text { RSFE }}{M A D} \\
& M A D=\frac{\sum \text { (absoluteforecasterror) }}{n}
\end{aligned}
$$

Keterangan:

$n \quad=$ banyaknya periode data

Tracking signal (TS) yang positif menunjukkan bahwa nilai aktual lebih besar dari ramalan, sedangkan TS negatif menunjukkan bahwa nilai aktual lebih kecil dari ramalan. TS dapat disebut "baik" jika RSFE bernilai rendah dan mempunyai positive error yang sama banyaknya dengan negative error sehingga pusat dari TS mendekati nol. Jika TS telah dihitung, maka peta kontrol TS yang memiliki batas kontrol atas dan batas kontrol bawah dapag dibangun.

Beberapa ahli sistem peramalan seperti George Plossl dan Oliver Wight menyarankan untuk menggunakan nilai TS maksimal +4 , sebagai batas-batas pengendali untuk TS. Jika TS berada diluar batas-batas pengendali tersebut maka model ramalan perlu ditinjau kembali, karena akurasi peramalan tidak dapat diterima.

C. Alur Sistem

Alur sistem informasi peramalan dapat digambarkan dalam bentuk flowchart dalam Gambar 1.

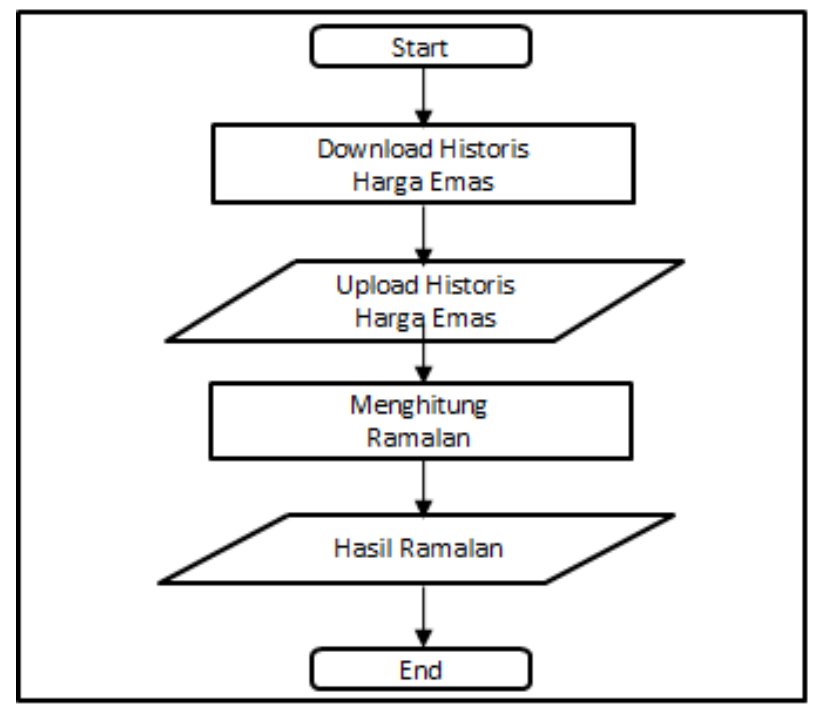

GAMBAR I. ALUR SISTEM INFORM ASI PERAM ALAN 
Jurnal INTENSIF, Vol.1, No.1, Februari 2017

ISSN: $2549-6824$

Pertama kali data historis harga emas Antam didownload dari situs Antam seperti terlihat dalam Gambar 2.

\begin{tabular}{|c|c|c|c|c|c|c|c|c|c|c|c|}
\hline \multicolumn{6}{|c|}{ Select period: } & & \multicolumn{3}{|c|}{ Frequency: } & \multicolumn{2}{|l|}{ Format: } \\
\hline \multirow{2}{*}{$\begin{array}{l}\text { From } \\
\text { To }\end{array}$} & 1 & $\mathbf{v}$ & Jan $\mathbf{v}$ & 2010 & & & \multicolumn{2}{|c|}{ Monthly $\mathbf{v}$} & & \multicolumn{2}{|l|}{ Excel $(2000->) \mathbf{v}$} \\
\hline & 20 & & Jun $\mathbf{v}$ & 2016 & $\mathbf{v}$ & & & & & & \\
\hline & & & & & & & & & & \multicolumn{2}{|l|}{ Search } \\
\hline Date & & Prev & Open & High & Low & Close & Chg. & $\%$ & Volume & Value & $\Delta$ \\
\hline $2016-06-2$ & & 735 & 740 & 760 & 735 & 735 & 0 & 0.00 & $162,991,919$ & \multicolumn{2}{|l|}{$121,460,316,560$} \\
\hline 2016-06-1 & & 720 & 705 & 780 & 680 & 735 & 15 & 2.08 & $1,021,377,761$ & \multicolumn{2}{|c|}{$774,547,579,416$} \\
\hline 2016-06-C & & 650 & 660 & 740 & 660 & 720 & 70 & 10.77 & $876,431,025$ & \multicolumn{2}{|c|}{$613,040,407,875 z$} \\
\hline $2016-05-3$ & & 670 & 670 & 685 & 640 & 650 & -20 & -2.99 & $430,477,451$ & $281,999,751,405$ & 1 \\
\hline
\end{tabular}

GAMBAR II. FORM DOWNLOAD DATA HISTORIS HARGA EMAS

Data yang akan didownload adalah data bulanan historis harga emas. Data yang dihasilkan sesuai dengan format yang dipilih yaitu excel 2000 degnan ekstensi file xls. Selanjutnya file excel tersebut diupload melalui aplikasi peramalan untuk diproses. Untuk pemrosesan data digunakan bahasa pemrograman PHP dan database MySql. Hasil pemrosesan data tersebut adalah ramalan kedepan untuk enam bulan kedepan.

\section{Hasil \& Pembahasan}

\section{A. Data Historis Harga}

Data historis harga emas Antam hasil download dari situs PT Antam (Persero) Tbk diurutkan secara ascending berdasarkan tanggal. Untuk mempermudah pembacaan periode maka ditambahkan satu kolom periode didepan terlihat dalam Tabel 1.

TABEL I. DATA HISTORIS HARGA EMAS ANTAM

\begin{tabular}{ccc}
\hline No & Date & Price \\
\hline 1 & $2010-01-04$ & 2125 \\
2 & $2010-02-01$ & 2075 \\
3 & $2010-03-01$ & 2400 \\
4 & $2010-04-01$ & 2450 \\
5 & $2010-05-03$ & 2025 \\
$\ldots$. & $\ldots$ & $\ldots$ \\
73 & $2016-01-04$ & 329 \\
74 & $2016-02-01$ & 364 \\
75 & $2016-03-01$ & 464 \\
76 & $2016-04-01$ & 760 \\
77 & $2016-05-02$ & 650 \\
78 & $2016-06-01$ & 735 \\
\hline
\end{tabular}


Jurnal INTENSIF, Vol.1, No.1, Februari 2017

ISSN: $2549-6824$

\section{B. Upload Data Historis Harga}

Selanjutnya data historis dalam Tabel 1 diupload menggunakan aplikasi sistem informasi peramalan harga emas Antam. Proses upload terlihat dalam Gambar 3.

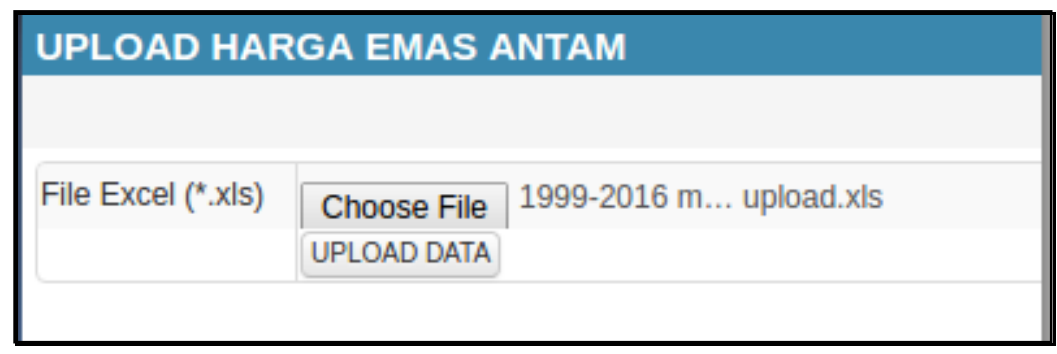

GAMBAR III. FORM UPLOAD DATA HISTORIS HARGA EMAS

Data historis harga emas dalam Gambar 3 selanjutnya diproses untuk dimasukkan dalam database.

Script yang digunakan untuk proses upload data historis harga emas kedalam database terlihat dalam

Gambar 4.

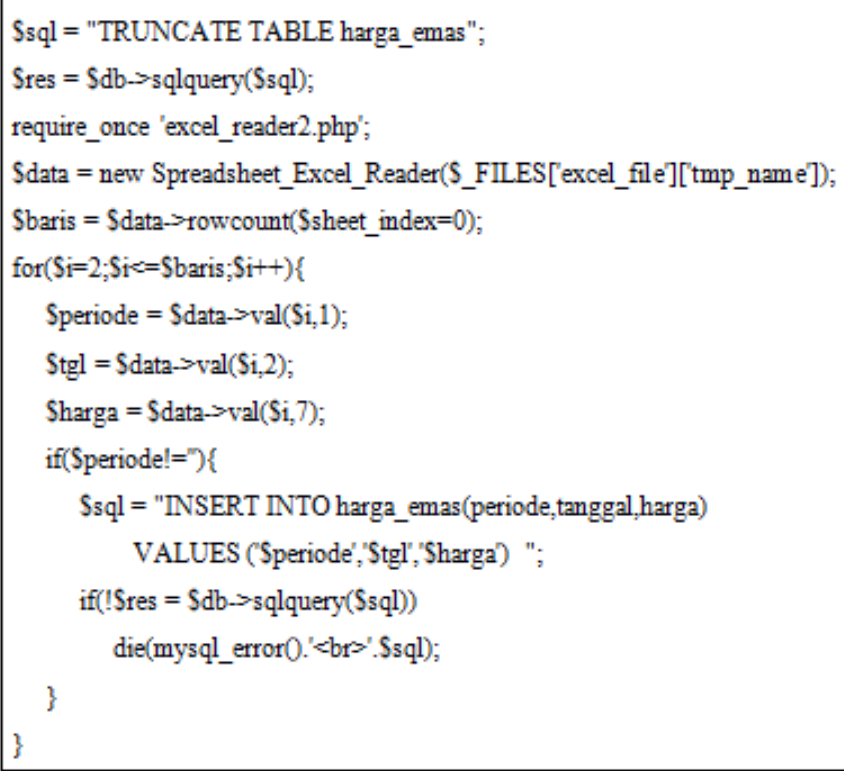

GAMBAR IV. SCRIPT PROSES UPLOAD DATA HISTORIS HARGA EMAS

C. Hasil Ramalan

\section{Peramalan Ke dalam}

Pada penelitian ini menggunakan nilai $\alpha=0,2$ dan $\gamma=0,3$ [1]. Perhitungan ramalan terhadap data dalam Tabel 1 dapat dijelaskan dengan mengambil contoh perhitungan ramalan untuk data pada periode ke-5 sebagai berikut:

$S_{4}=0,2 * 2.450+(1-0,2)(2.400-27,5)=2.148$

$b_{4}=0,3(2.148-2.100)+(1-0,3)(-27,5)=-4,85$

$F_{5}=2.418-4,85=2.107,58$

Hasil perhitungan ramalan untuk seluruh data dalam Tabel 1 terlihat dalam Tabel 2 
Jurnal INTENSIF, Vol.1, No.1, Februari 2017

ISSN: 2549-6824

TABEL II. HASIL PERAM ALAN HARGA EM AS ANTAM

\begin{tabular}{cccccc}
\hline \hline $\mathbf{t}$ & Date & Price & $\begin{array}{c}\text { Single } \\
\text { Smoothing }\end{array}$ & Trend Factor & Forecast \\
\hline 1 & $2010-01-04$ & $2.125,00$ & $2.125,0000$ & $-50,0000$ & $2.075,00$ \\
2 & $2010-02-01$ & $2.075,00$ & $2.075,0000$ & $-50,0000$ & $2.025,00$ \\
3 & $2010-03-01$ & $2.400,00$ & $2.100,0000$ & $-27,5000$ & $2.072,50$ \\
4 & $2010-04-01$ & $2.450,00$ & $2.148,0000$ & $-4,8500$ & $2.143,15$ \\
5 & $2010-05-03$ & $2.025,00$ & $2.119,5200$ & $-11,9390$ & $2.107,58$ \\
$\ldots$ & $\ldots$ & $\ldots$ & $\ldots$ & $\ldots$ & $\ldots$ \\
74 & $2016-02-01$ & 364,00 & 196,4904 & $-56,6278$ & 139,86 \\
75 & $2016-03-01$ & 464,00 & 204,6901 & $-37,1795$ & 167,51 \\
76 & $2016-04-01$ & 760,00 & 286,0085 & $-1,6301$ & 284,38 \\
77 & $2016-05-02$ & 650,00 & 357,5026 & 20,3072 & 377,81 \\
78 & $2016-06-01$ & 735,00 & 449,2478 & 41,7386 & 490,99 \\
\hline
\end{tabular}

\section{Peramalan Kedepan}

Dari data dalam Tabel 1 permalan kedepan dilakukan mulai pada periode ke-79. Dalam penelitian ini peramalan dilakukan untuk dua bulan kedepan yaitu periode ke-79 dan ke-80.

Dengan menggunakan Persamaan (3) perhitungan ramalan kedepan periode ke-78 dapat dijelaskan sebagai berikut:

Periode acuan $(\mathrm{t})$ adalah periode ke-79, nilai variabel $\mathrm{m}$ adalah 1

$F_{78+1}=S_{78}+1 * b_{78}$

$F_{79}=449,2478+1 * 41,7386=490,9864$

Perhitungan ramalan kedepan periode ke-80 dapat dijelaskan sebagai berikut:

Periode acuan (t) adalah periode ke-78, nilai variabel $\mathrm{m}$ adalah 2

$F_{78+2}=S_{78}+2 * b_{78}$

$F_{80}=449,2478+2 * 41,7386=532,725$

D. Pengujian Kesalahan Peramalan`

Pengujian kesalahan peramalan menggunakan Persamaan (11). Hasil pengujian kesalahan peramalan ditunjukkan dalam Tabel 3.

Dari Tabel 3 didapatkan nilai BIAS=40,55 MAD=136,58 MSE=29.801,63 MAPE=12,66

Perhitungan kesalahan peramalan dalam Tabel 3 dapat dijelaskan dengan mengambil contoh perhitungan pada periode ke-5 sebagai berikut:

Dengan menggunakan Persamaan (9) diperoleh

$\mathrm{PE}_{5}=(2025-2107,58) / 2025 * 100 \%=-82,581 \%$

Nilai absolute percentage error adalah

$\mathrm{APE}_{5}=|-82,581 \%|=82,581 \%$

Dengan menggunakan Persamaan (10) diperoleh 
Jurnal INTENSIF, Vol.1, No.1, Februari 2017

ISSN: 2549-6824

$$
\begin{aligned}
\text { MAPE } & =(2,35 \%+2,41 \%+13,65 \%+12,52 \%+\ldots+63,90 \%+62,58 \%+41,88 \%+33,20 \%) / 78 \\
& =12,66 \% \%
\end{aligned}
$$

Sehingga tingkat keakuratan peramalan adalah $100 \%-12,66 \%=87,34 \%$

TABEL III. PERHITUNGAN KESALAHAN PERAMALAN

\begin{tabular}{cccccc}
\hline $\mathbf{t}$ & Date & Price & Forecast & Error & $\begin{array}{c}\text { Absolute } \\
\text { Percentage } \\
\text { Error (\%) }\end{array}$ \\
\hline 1 & $2010-01-04$ & $2.125,00$ & $2.075,00$ & 50,0000 & 2,35 \\
2 & $2010-02-01$ & $2.075,00$ & $2.025,00$ & 50,0000 & 2,41 \\
3 & $2010-03-01$ & $2.400,00$ & $2.072,50$ & 327,5000 & 13,65 \\
4 & $2010-04-01$ & $2.450,00$ & $2.143,15$ & 306,8500 & 12,52 \\
5 & $2010-05-03$ & $2.025,00$ & $2.107,58$ & $-82,5810$ & 4,08 \\
$\ldots$ & $\ldots$ & $\ldots$ & $\ldots$ & $\ldots$ & $\ldots$ \\
74 & $2016-02-01$ & 364,00 & 139,86 & 224,1374 & 61,58 \\
75 & $2016-03-01$ & 464,00 & 167,51 & 296,4894 & 63,90 \\
76 & $2016-04-01$ & 760,00 & 284,38 & 475,6217 & 62,58 \\
77 & $2016-05-02$ & 650,00 & 377,81 & 272,1902 & 41,88 \\
78 & $2016-06-01$ & 735,00 & 490,99 & 244,0136 & 33,20 \\
\hline
\end{tabular}

E. Pengujian Tracking Signal

Perhitungan Tracking Signal terlihat dalam Tabel 5. Dari Tabel 5 diperoleh 60 dari 78 data ramalan memiliki nilai tracking signal berada diluar batas-batas pengendalian.

TAB EL IV. Tracking Signal Peramalan

\begin{tabular}{cccccccc}
\hline $\mathbf{t}$ & Price & Forecast & Error & $\begin{array}{c}\text { Absolute } \\
\text { Percentage } \\
\text { Error (\%) }\end{array}$ & RSFE & MAD & $\begin{array}{c}\text { Tracking } \\
\text { Signal }\end{array}$ \\
\hline 1 & $2.125,00$ & $2.075,00$ & 50,0000 & 2,35 & 50,00 & 50,00 & 1,0000 \\
2 & $2.075,00$ & $2.025,00$ & 50,0000 & 2,41 & 100,00 & 50,00 & 2,0000 \\
3 & $2.400,00$ & $2.072,50$ & 327,5000 & 13,65 & 427,50 & 142,50 & 3,0000 \\
4 & $2.450,00$ & $2.143,15$ & 306,8500 & 12,52 & 734,35 & 183,59 & 4,0000 \\
5 & $2.025,00$ & $2.107,58$ & $-82,5810$ & 4,08 & 651,77 & 163,39 & 3,9891 \\
$\ldots$ & $\ldots$ & $\ldots$ & $\ldots$ & $\ldots$ & $\ldots$ & $\ldots$ & $\ldots$ \\
74 & 364,00 & 139,86 & 224,1374 & 61,58 & $1.874,67$ & 126,55 & 14,8132 \\
75 & 464,00 & 167,51 & 296,4894 & 63,90 & $2.171,16$ & 128,82 & 16,8543 \\
76 & 760,00 & 284,38 & 475,6217 & 62,58 & $2.646,79$ & 133,38 & 19,8435 \\
77 & 650,00 & 377,81 & 272,1902 & 41,88 & $2.918,98$ & 135,19 & 21,5923 \\
78 & 735,00 & 490,99 & 244,0136 & 33,20 & $3.162,99$ & 136,58 & 23,1583 \\
\hline
\end{tabular}


Jurnal INTENSIF, Vol.1, No.1, Februari 2017

ISSN: $2549-6824$

\section{KeSimpulan \& SARAN}

Dari hasil analisa dan pengujian diperoleh kesimpulan (1) Pola historis harga emas Antam memiliki trend dengan kecenderungan menurun sehingga digunakan metode peralaman Double Exponential Smoothing. (2) Dari hasil pengujian diperoleh nilai kesalahan peramalan 12,66\% atau memiliki keakuratan peramalan 87,34\%. (3) Pengujian dengan Tracking Signal menunjukkan 60 dari 78 data berada diluar batas-batas pengendalian.Isi kesimpulan merupakan jawaban dari tujuan penelitian bukan rangkuman hasil penelitian. Kesimpulan dan saran dibuat secara singkat, jelas, dan padat didasarkan pada hasil penelitian. Kesimpulan dan Saran berupa paragraf. Perlu dipilih atau dikembangkan metode peramalan selain Double Exponential Smoothing untuk meramalkan harga emas Antam sehingga nilai Tracking Signal dalam setiap data ramalan berada dalam batas-baas pengendalian.

\section{Daftar Pustaka}

[1] PT ANTAM (Persero) Tbk, "Historis Harga Emas Antam," PT ANTAM Tbk. [Online]. Available: http://www.antam.com/index.php?option=com_wrapper\&Itemid=163\&lang=id. [Accessed: 21Jun-2016].

[2] H. Anggraini, "Sistem Pemantau Distribusi Stok Menggunakan Pendekatan Continous Review dan Metode Single Exponential Smoothing." Ilmu Komputer FMIPA Universitas Gadjah Mada.

[3] T. Andriyanto, "Inventory Control Terintegrasi Menggunakan Periodic Review Policy dan Triple Exponential Smoothing," Universitas Gadjah Mada, 2015.

[4] T. Andriyanto, "Pengendalian Persediaan Barang Dengan Pendekatan Periodic Review dan Adaptive Response Rate Single Exponential Smoothing di Arta Swalayan Kediri," in Semnasteknomedia, Yogyakarta, 2016, vol. 2016, p. 1.3-67-1.3-71.

[5] L. Wu, S. Liu, and Y. Yang, "Grey double exponential smoothing model and its application on pig price forecasting in China," Appl. Soft Comput., vol. 39, pp. 117-123, Feb. 2016.

[6] S. Riyadi, "Aplikasi Peramalan Penjualan Obat Menggunakan Metode Pemulusan (Studi Kasus: Instalasi Farmasi RSUD dr Munjani)," in Semnasteknomedia, Yogyakarta, 2015, p. 5.3-1-5.3-6.

[7] C. Baktiar, A. Wibowo, and R. Adipranata, "Pembuatan Sistem Peramalan Penjualan Dengan Metode Weighted Moving Average dan Double Exponential Smoothing Pada UD Y,” J. Infra, vol. 3, no. 1,2015 .

[8] W. Wahyani, and A. Syaichu, "Penerapan Petode Peramalan Sebagai Alat Bantu Untuk Menentukan Perencanaan Produksi di PT SKK," Spektrum Ind., vol. 13, no. 2, pp. 115 - 228, 2015.

[9] D. Simchi-Levi, P. Kaminsky, and E. Simchi-Levi, Designing and Managing The Supply Chain Third Edition. McGraw-Hill, 2000. 